Dialectica, Vol. 72, 2018, pp. 69-100.

\title{
Towards an Ecumenical Theory of Normative Reasons
}

\author{
Caj Sixten STRANDBERG ${ }^{\dagger}$
}

\section{ABSTRACT}

A theory of normative reasons for action faces the fundamental challenge of accounting for the dual nature of reasons. On the one hand, some reasons appear to depend on, and vary with, desires. On the other hand, some reasons appear categorical in the sense of being desire-independent. However, it has turned out to be difficult to provide a theory that accommodates both these aspects. Internalism is able account for the former aspect, but has difficulties to account for the latter, whereas externalism is vulnerable to the reverse problem. In this paper, I outline an ecumenical view that consists of two parts: First, I defend a distinction between requiring reasons and justifying reasons in terms of their different connections to rationality. Second, I put forward a subjectivist, procedural, view of rationality. The ecumenical alternative, I argue, is able to accommodate the mentioned duality within a unified theory. In outlining this view, I also suggest that it has a number of other significant advantages.

\section{Introduction}

A theory of normative reasons for action faces the fundamental challenge of accounting for the dual nature of reasons. On the one hand, some of an agent's reasons seem to depend on, and vary with, her desires, at least in the minimal sense that her desires can function as tiebreakers between conflicting reasons. On the other hand, some of an agent's reasons, particularly her moral reasons, seem to be categorical in the basic sense that they apply to her quite independently of her particular desires. However, it has turned out to be quite difficult to accommodate both these aspects. Internalism is able to account for the former aspect, but has difficulties to account for the latter, whereas externalism appears to face the reverse problem. In this paper, I outline an ecumenical view of reasons with the aim of accounting for this duality within a unified theory. In addition, I suggest that the ecumenical view has a number of other significant advantages.

The paper proceeds as follows. In the next section, I suggest that internalism can be understood as a combination of two claims: a certain standard conception of the connection between reasons and rationality, and a subjectivist, procedural, view of rationality. In this section, I also provide a characterization of externalism. In Section 3, I consider Joshua Gert's important distinction between the requiring and justifying functions of reasons. As Gert points out, the standard conception of the connection between reasons and rationality entails that reasons have the sole function to rationally require actions. In contrast to what is possible on this conception, he argues that reasons have two functions: to rationally require and to rationally justify actions. In my mind, Gert's distinction is compelling, and I set out to formulate a position which accommodates it. The remainder of the paper is devoted to outlining the ecumenical theory of reasons, ER. In Section 4, I outline its first part: A distinction between

\footnotetext{
$\dagger$ Department of Philosophy, Classics, History of Art and Ideas, University of Oslo, P.O. Box 1020, Blindern, 0315 Oslo, Norway. Email address: caj.strandberg@ifikk.uio.no.
} 
Dialectica, Vol. 72, 2018, pp. 69-100.

requiring and justifying reasons in terms of their different connections to rationality. In Section 5, I outline its second part: A subjectivist, procedural, view of rationality. The basic idea in $E R$ is this: The distinction between the requiring and justifying functions of reasons in conjunction with subjectivism about rationality allows that some reasons are based on desires while some reasons are based on external, desire-independent, features of actions. The view I suggest is ecumenical in the sense that reasons have two sources: rational desires and external features of actions. However, while reasons have two sources, the view provides a unified account of reasons because it rests on a particular, singular notion of rationality. ${ }^{1}$ According to $E R$, both an agent's requiring reasons and some of her justifying reasons might be based on her rational desires. More importantly, however, according to ER some of an agent's justifying reasons might be based on external features that are entirely independent of her desires. In other words, on this view justifying reasons might be desire-independent even according to subjectivism about rationality. In Section 6, I combine the two parts of ER. In Sections 7-9, I argue that $E R$ has significant advantages compared to its main alternatives. First, in contrast to internalism and externalism, it provides a solution to the fundamental challenge mentioned above. That is, some of an agent's reasons depend on, and vary with, her desires, whereas some of her reasons, most notably her moral reasons, are categorical. Second, it provides a plausible interpretation of the notion that we have different rational commitments to ourselves and to others. Third, it is able to account for the notion that desires might function as tie-breakers. In section $\mathbf{1 0}$, I tentatively propose that categorical moral reasons are based on an external feature concerning the fulfilment of other agents' rational desires. The proposal indicates, I maintain, that subjectivism has unexpected resources to vindicate the existence of categorical moral reasons.

\section{Internalism, Externalism, and Rationality}

It is standardly assumed in moral philosophy that there is a necessary connection between the concept of normative reasons and the concept of practical rationality. Moreover, a particular instance of this notion is presumed in much theorizing about reasons: If an agent $\mathrm{S}$ has a reason to $\phi$, then she needs to have some appropriate desire with regard to фing if she is to count as fully rational. The following is a simple version of this basic idea: ${ }^{2}$

\footnotetext{
${ }^{1}$ For related but distinct views, see Lillehammer (1999a, 186-190) and Chang (2013, 163-187).

${ }^{2}$ See Cullity and Gaut $(1997,3)$. Many metaethicists explicitly or implicitly regard this claim as a platitude. For some examples, see Williams (1981, 101-113); Darwall (1983, 80-83); Parfit (1997, 99); Smith (1994, 62), 150; Korsgaard (1996, 23); Velleman (1996, 694); Tilley (1997, 105-127); Hampton (1998, 73); Wallace (1999, 217-218); Setiya (2004, 268-269); Finlay (2009, 2-3); Goldman (2009, 7, 9-10); Bedke (2010, 39-40), and Markovits (2014, Ch. 1).
} 
Dialectica, Vol. 72, 2018, pp. 69-100.

Standard claim: If an agent $S$ has a reason to $\phi$, then she would have a desire to $\phi$ if she were rational.

There are alternative formulations of this basic conception, but since the differences between them are not important for my arguments, I will focus on this simple claim. ${ }^{3}$

As indicated, I will later suggest that the standard claim should be rejected in favour of a distinction between requiring and justifying reasons. However, there are certain assumptions I will make throughout the paper when talking about reasons and rationality. First, I will be concerned with S's real normative reasons rather than her apparent or motivating reasons. This means that S's rationality should be understood as her rationality on the assumption that she is fully informed about all relevant non-normative facts, in the sense that she has all relevant true non-normative beliefs and no relevant false non-normative beliefs. Second, while I will be concerned with the connection between S's reasons and her rationality, this should not be understood to entail that reasons can be reduced to rationality or that rationality is explanatory prior to reasons. Accordingly, the claims I discuss do not take any stand on the issue whether reason or rationality is the fundamental normative concept. Third, I will be concerned with S's pro tanto reasons rather than with her pro toto, or all-things-considered, reasons. Lastly, as I use it, 'desire' refers to a variety of dispositional and occurrent mental states which all have in common a motivating function, such as 'wanting', 'caring', 'being committed', 'valuing', etc. The term is not used in a way presuming a particular view of such states, e.g. a Humean theory of motivation.

A fundamental issue in the debate about normative reasons concerns whether they depend on desires, which constitutes the dividing line between internalism and externalism. As noticed, the standard claim is presumed in much theorizing about reasons. It is plausible to think that internalism can be formulated as the combination of the standard claim and what I will call 'subjectivism' about rationality:

Internalism: (R) If an agent $\mathbf{S}$ has a reason to $\phi$, then she would have a desire to $\phi$ if she were rational. (S) Rationality is understood in accordance with subjectivism about rationality.

According to subjectivism, an agent $S^{\prime}$ 'S rationality with respect to her desires amounts to a version of informed procedural rationality. More precisely, $\mathrm{S}$ is rational in this respect insofar as she has a set of desires that she would have if she (1) were fully informed about all relevant

\footnotetext{
${ }^{3}$ According to an alternative formulation, if $S$ has a reason to $\phi$, then her ideally rational counterpart $S^{*}$ would desire that S фs (Smith (1995, 109-131)).
} 
Dialectica, Vol. 72, 2018, pp. 69-100.

non-normative facts and (2) were to go through a process of rational deliberation which takes its point of departure in her set of actual desires. A plausible consequence of subjectivism is that a set of desires which $\mathrm{S}$ needs to have in order to be rational is counterfactually dependent on her set of actual desires. ${ }^{4}$ That is, if her set of actual desires had been different from what it is, a set of desires which she needs to have to be rational might also be different. Consequently, internalism implies that whether $\mathrm{S}$ has a reason to $\phi$ might depend on, and vary with, her actual desires.

According to externalism, whether an agent $S$ has a reason to $\phi$ is not contingent on her actual desires in this manner. Externalism is often associated with what might be called 'objectivism' about rationality, e.g. a substantive view of rationality or a more demanding version of a procedural view of rationality. In order to be rational according to objectivism, $\mathrm{S}$ needs to have a certain particular set of desires that is entirely independent of her set of actual desires. Consequently, whether $\mathrm{S}$ has a reason to $\phi$ would not depend on, or vary with, her actual desires in the indicated way. ${ }^{5}$ There are different versions of externalism, inter alia depending on what version of objectivism they involve. It is often objected, however, that externalism is more philosophically problematic than internalism. On one type of worry, reasons that are entirely independent of actual desires would be ontologically 'queer'. On another type of worry, the objectivist claim that $S$, in order to be rational, needs to have particular desires which are entirely independent of her actual desires, entails an implausibly demanding notion of rationality. ${ }^{6}$

\section{Two Functions of Reasons}

In the last section, I mentioned a fundamental issue about normativity that has been subject to much discussion: whether reasons depend on desires. There is however another issue of this type which has not been discussed to the extent it deserves: whether reasons only have one function with regard to rationality. Recall:

\footnotetext{
${ }^{4}$ For different formulations of internalism, see e.g. Williams (1981, 104-105); Tilley (1997, 105-127); Joyce (2001, Ch. 3-5); Finlay (2006, 1-20) and (2008, 347-369); Shemmer (2007, 326-348); Svavarsdóttir (2008, 1-33); Goldman (2009), and Ridge (2014, Ch. 8). For two socially oriented variations of internalism, see Manne (2014, 89-117), and Sinclair (2017, 209-229). The two claims above merely specify S's rationality with regard to her desires, and a full account of rationality would need to include further components. The contention that a set of desires which $S$ needs to have to be rational is counterfactually dependent on her set of actual desires is a natural corollary of subjectivism. If $\mathrm{S}$ is rational insofar as she has a set of desires she would have were she to go through a process of informed rational deliberation which takes its starting point in her set of actual desires, it seems extremely plausible to think that the former varies with the latter. A complication with subjectivism is that the mentioned type of process need not result in one unique set of desires. I will return to this point in Section $\mathbf{5}$.

${ }^{5}$ See e.g. Quinn (1993, 228-255); Raz (1999, Ch. 4-5); Dancy (2000, ); Shafer-Landau (2003, Part IV); Fitzpatrick (2004, 285-318); Enoch (2011, Ch. 2-3); Bedke (2010, 39-57); Parfit (2011), and Scanlon (2014).

${ }^{6}$ For the first type of worry, see e.g. Mackie $(1977,39-40)$; for the second one, see e.g. Williams (1981, 101-113).
} 
Dialectica, Vol. 72, 2018, pp. 69-100.

Standard claim: If an agent $S$ has a reason to $\phi$, then she would have a desire to $\phi$ if she were rational.

The standard claim entails that $S$ 's reason to $\phi$ has the function of making her rationally required to have a desire to $\phi$. In other words, it entails that if $S$ has a reason to $\phi$, but does not have any desire to $\phi$, she is irrational. However, it might be objected that it is conceptually possible, at least with regard to some type of normative reasons, that $\mathrm{S}$ has a reason to $\phi$ even if she would not be irrational were she to lack a desire to $\phi$. In particular, it seems possible that $S$ might have a moral reason to $\phi$, but that she need not be irrational if she lacks any desire to $\phi .^{7}$ For example, it seems possible to conceive of an agent $\mathrm{S}$ who has a genuine moral reason to help another agent $\mathrm{T}$ in need, but who is not necessarily irrational if she lacks a desire to do so. Indeed, we do not seem to think that a complete egoist who does not care about moral matters has to be irrational, although we leave open the option that she might be. It seems that the most natural thing to say about such an agent is not that she has to be irrational, but rather that she is immoral or fails in moral sensitivity. Similarly, if an agent has a moral reason to $\phi$, but does not have any desire to $\phi$, we might criticize her. However, we would not necessarily criticize her for being irrational, but rather for making a type of moral failure. It is worth stressing that what is at issue is whether we should leave conceptual space for S having a certain type of reason to $\phi$ without being irrational in lacking a desire to $\phi$. Whether we should accept that there actually are such reasons will ultimately be determined by the explanatory value of the theory in question. Accordingly, many views that might appear to be at variance with the mentioned possibility are presumably most charitably interpreted as defending substantive theories about reasons and rationality, rather than a conceptual claim. ${ }^{8}$ In the light of these considerations, it is plausible to think that it is those who contest this possibility that need to argue for their position.

It is similar considerations that motivate Joshua Gert's original and resourceful theory of reasons. ${ }^{9}$ Gert argues that an agent $S$ might have a moral reason to $\phi$ without being rationally required to $\phi$, and that this is so irrespective of whether she has any countervailing reason not to $\phi$. In order to account for this notion, Gert suggests that reasons have two

\footnotetext{
${ }^{7}$ Cf. Foot (1978, Ch. 11); Joyce (2001, 62-63); Gert (2004, esp. Ch. 2); Scanlon (2014, 105-107); Copp (2015, 134159), and Dorsey (2016, Ch. 3-4). Similarly, it seems possible to conceive of an agent $S$ who has a genuine moral reason to $\phi$, but whose fully idealized self $S^{*}$ need not fail in rationality if she lacks a desire that $S \phi s$.

${ }^{8}$ There are arguments, most notably in the Kantian tradition, to the effect that an agent who has a moral reason to $\phi$, but does not $\phi$, or does not have any inclination to $\phi$, is somehow irrational. As far as I understand, they reach this conclusion via controversial premises that do not receive immediate support from our pre-philosophical conception of the connection between moral reasons and rationality.

${ }^{9}$ Gert provides a systematic defence of his view in Gert (2004) and has developed it in later works; see e.g. Gert (2007, 319-332); Gert (2009a, 319-332); Gert (2009b, 718-742), and Gert (2012). For related distinctions, see Raz (1999, 99-105); Dancy (2004, 91-118), and Scanlon (2014, 105-107).
} 
Dialectica, Vol. 72, 2018, pp. 69-100.

functions: to make actions rationally required and to make them rationally justified. Gert formulates the distinction thus:

[Requiring function] A consideration is a reason if it can make it irrational to do something that would, without that consideration, be rationally permissible.

[Justifying function] A consideration is a reason if it can make it rationally permissible to perform actions that would be irrational without it. ${ }^{10}$

This distinction allows that $\mathrm{S}$ might have a moral reason to $\phi$ without being rationally required to $\phi$ (irrespective of whether she has any countervailing reason not to $\phi$ ), since she might have a reason to $\phi$ given that it is rationally permissible for her to $\phi$.

The distinction can be employed in different manners, for example by combining it with subjectivism or objectivism about rationality. Gert's view is objectivist:

An action is objectively irrational iff it involves a nontrivial risk, to the agent, of nontrivial pain, disability, loss of pleasure, or loss of freedom, or premature death without a sufficient chance that someone (not necessarily the agent) will avoid one of these same consequences, or will get pleasure, ability, or freedom, to a compensating degree. $^{11}$

The resulting view captures a fundamental aspect of our common sense notion of an agent S'S rational commitments in relation to different types of actions. On the one hand, it seems plausible to think that what $S$ is rationally required to do typically concerns what is of most importance to herself, such as her own basic well-being. On the other hand, it seems plausible to think that what $S$ is rationally permitted, but not required, to do typically concerns the wellbeing of others. In addition, it captures the common sense notion that $\mathrm{S}$ need not be irrational if she performs an action which serves the well-being of others at the expense of her own wellbeing. ${ }^{12}$ This is something that she might be rationally permitted, but not rationally required, to do.

\section{First Part of ER: Requiring Reasons and Justifying Reasons}

We have seen that internalism can be characterized as a combination of two claims: a certain standard conception of the connection between reasons and rationality, and subjectivism about rationality. We then saw that there are grounds to think that reasons might have two functions with regard to rationality: to require and to justify. This opens up the possibility of a

\footnotetext{
${ }^{10}$ Gert $(2004,66-67)$.

${ }^{11}$ Gert $(2004,141)$. Cf. Gert (2009a, 321). (Gert uses 'objective' in another sense than I do.)

12 In Gert's view, all reasons that have rational requiring strength also have rational justifying strength. He argues further that a reason to serve someone else's well-being might have enough justifying strength to justify acting against a self-interested reason.
} 
Dialectica, Vol. 72, 2018, pp. 69-100.

position which combines this distinction with subjectivism. In this section, I spell out the first part of this ecumenical view about reasons $(E R)$ : an account of the connection between reasons and rationality which accommodates the two functions of reasons.

In contrast to Gert, I will distinguish between two types of reasons-rationally requiring reasons and rationally justifying reasons-so as to capture these two functions, since this will make it easier to formulate relevant claims about the connection between reasons and rationality. ${ }^{13}$ Importantly, this distinction is not intended to be exclusive. That is, one and the same reason might constitute both a requiring and a justifying reason, in which case it has both a requiring and a justifying function. Moreover, an agent $\mathrm{S}$ might have both a requiring and a justifying reason to perform a certain action. There are also more substantive differences between Gert's formulation of the distinction and my own. Whereas Gert understands it in terms of what $\mathrm{S}$ is rationally required or permitted to do, I will understand it in terms of what she is rationally required or justified to have a desire to do. ${ }^{14}$ The latter will make it easier to express the difference between the standard claim and a view according to which reasons have two functions. In addition, it will make it easier to formulate claims about what $\mathrm{S}$ has a pro tanto reason to do.

The standard claim states that if an agent $S$ has a reason to $\phi$, she would have a desire to $\phi$ if she were rational, which entails that $S$ is irrational if she lacks a desire to $\phi$. In order to formulate a view that allows for both requiring and justifying reasons, we need to find a way of expressing the connection between reasons and rationality which avoids this implication. Let us start with observing that we might not only say that $\mathrm{S}$ would have a desire to $\varphi$ if she were rational. We might also say that it would be rational for $S$ to have a desire to $\varphi$. We can next observe that claims about rationality are ambiguous in a certain respect. The claim that it would be rational for $S$ to have a desire to $\phi$ can be taken to entail either (a) that it would be irrational for $\mathrm{S}$ to lack a desire to $\phi$, or (b) that it would not be irrational for $\mathrm{S}$ to have a desire to $\phi$. We can employ (a) to define that ' $S$ is rationally required to have a desire to $\phi$ ' and (b) to define that ' $\mathrm{S}$ is rationally justified to have a desire to $\phi$ '. (I will use the expression 'S is

\footnotetext{
${ }^{13}$ Different types of distinctions between requiring and justifying strengths can be made within the normative sphere. Accordingly, we might distinguish not only between rational requiring and justifying strength, but also between moral requiring and justifying strength. Douglas $W$. Portmore has recently argued that the latter distinction is essential for understanding the interaction between moral and non-moral reasons: Portmore (2011, Ch. 5), and Portmore (2013, 436-459). For another employment of this distinction, see Dorsey (2016, Ch. 5). In the present paper, I am referring to rationally requiring and justifying reasons, but I also think we should distinguish between morally requiring and justifying reasons. Importantly, $E R$ is compatible with a rationally justifying reason consisting in a morally requiring reason.

${ }^{14}$ As indicated earlier, as I use it, 'desire' does not entail any particular view about motivational states; in particular, I do not want to commit myself to a Humean theory of motivation.
} 
Dialectica, Vol. 72, 2018, pp. 69-100.

rationally justified to have' in order for the definitions of the two notions to be congruent with one another.)

We are now in the position to formulate a view about the connection between reasons and rationality which makes room for both requiring and justifying reasons. In the formulations below, we might consider 'feature $F$ ' as what provides $S$ 's reason to $\phi$. First, there is a general claim about reasons in terms of 'rational for' which holds for all normative reasons:

General reason claim (G): An agent $S$ has a reason to $\phi$ insofar as $\phi i n g$ has a feature $F$ which makes it rational for $S$ to have a desire to $\phi$.

Then there is a distinction between requiring reasons and justifying reasons depending on how 'rational for' is understood.

Requiring reasons $(\mathbf{R})$ : An agent $\mathrm{S}$ has a requiring reason to $\phi$ insofar as $\phi i n g$ has a feature $\mathrm{F}$ which makes $\mathrm{S}$ rationally required to have a desire to $\phi$.

Specification of $(\mathbf{R})$ : A feature $F$ makes an agent $S$ rationally required to have a desire to $\phi$ insofar as (i) it would be irrational for $S$ to lack a desire to $\phi$ if $\phi i n g$ has $F$, and (ii) it would not be irrational for $S$ to lack a desire to $\phi$ if $\phi i n g$ does not have $F .^{15}$

Justifying reasons (J): An agent $\mathrm{S}$ has a justifying reason to $\phi$ insofar as $\phi i n g$ has a feature $F$ which makes $S$ rationally justified to have a desire to $\phi$.

Specification of (J): A feature $\mathrm{F}$ makes an agent $\mathrm{S}$ rationally justified to have a desire to $\phi$ insofar as (i) it would not be irrational for $\mathrm{S}$ to have a desire to $\phi$ if $\phi i n g$ has $F$, and (ii) it would be irrational, or non-rational, for $S$ to have a desire to $\phi$ if $\phi$ ing does not have F. ${ }^{16} 17$

\section{Second Part of ER: Subjectivism about Rationality}

In this section, I spell out the second part of ER: A version of subjectivism about rationality. In particular, I consider what it means that an agent $S$ is rationally required, respectively rationally justified, to have a desire to $\phi$ on this view.

\footnotetext{
${ }^{15}$ (ii) holds ceteris paribus. That is, (ii) holds unless ping has some other feature $F^{\prime}$ such that it would be irrational for $\mathrm{S}$ to lack a desire to $\phi$.

${ }^{16}$ Importantly, (ii) holds ceteris paribus. That is, (ii) holds unless фing has some other feature F' such that it would not be irrational, or non-rational, for $\mathrm{S}$ to have a desire to $\phi$.

${ }^{17}$ In certain circumstances, it might be irrational for $S$ to have a desire to $\phi$ if $\phi i n g$ does not have F. However, we might also allow for the possibility that it, in certain circumstances, can be non-rational ('arational') for $S$ to have a desire to $\phi$ if ing does not have $F$. In that case, it would neither be irrational nor rational (not irrational) to have a desire to $\phi$. This point does not affect my arguments.
} 
Dialectica, Vol. 72, 2018, pp. 69-100.

\section{Subjectivism and the Notion of Desires ${ }_{R}$}

According to subjectivism, an agent $S$ is rational with respect to what desires to have insofar as she has a set of desires that she would have if she (1) were fully informed about all relevant non-normative facts and (2) were to go through a process of rational deliberation which takes its point of departure in her set of actual desires. On this picture, there are certain rational considerations that provide support for $\mathrm{S}$ having a set of desires. In a process of informed rational deliberation, $\mathrm{S}$ applies these considerations to her actual desires, and as a result comes to have such a set of desires. After such a process, $\mathrm{S}$ might have lost certain desires and obtained certain other desires. Let us define a set of $\operatorname{desires}_{R}$ as a set of desires that $S$ would have were she to go through this type of process.

There are different views about what the rational considerations consist in that are involved in a process of informed rational deliberation. However, they are often assumed to include the following. ${ }^{18}$ First, means-end reasoning. In particular, after such a process $S$ has desires for means that are necessary to satisfy her final desires, i.e. desires which have as their objects what she desires for their own sake, where these final desires also are members of the mentioned type of set. Second, careful exercise of imagination about different options. Third, coherence among desires. For example, after such a process $\mathrm{S}$ has general desires which explain and vindicate more specific desires. ${ }^{19}$ In Section 10, I will suggest that there is a further rational consideration pertaining to coherence.

In this context, a certain complication with regard to subjectivism should be noticed. ${ }^{20}$ As observed, an agent $\mathrm{S}$ who goes through a process of informed rational deliberation which takes its starting point in her set of actual desires will as a result have a set of desires ${ }_{R}$. However, we should leave open the possibility that there is not one unique set of this type. That is, we should make room for the possibility that such a process could result in various alternative sets of desires $s_{R}$. It is not essential for my arguments what conclusion subjectivists should draw from this possibility. However, it is plausible to think that $\mathrm{S}$ needs merely to have one such set of desires $_{R}$ in order to be rational. This suggestion has implications for both instrumental desires ${ }_{R}$ and final desires $s_{R}$ A process of informed rational deliberation could

\footnotetext{
${ }^{18}$ In the contemporary literature on normativity, there is an important ongoing debate as regards whether rational considerations should be understood as narrow or wide scope requirements. (For an excellent discussion of this debate, see Kiesewetter (2017, Ch. 3-5).) In the present paper, I will not take a stand on this issue. Although I formulate instrumental rational according to the first alternative, my claims below could be formulated in accordance with the latter. Moreover, the fact that subjectivism refers to coherence should not be taken to entail that the notion of rationality is reducible to the notion of coherence. It might for instance be argued that rationality is best understood in terms of responding to reasons in a manner which is able to account for the normative function of coherence. See e.g. Kiesewetter (2017, Ch. 7) and Lord (2017, 1109-1154). For a recent defence of understanding rationality in terms of coherence, see Wedgwood (2017).

${ }^{19} \mathrm{Cf}$. Michael Smith's notion of 'systematic justification of desires' (Smith $(1995,109-131)$ ).

${ }^{20}$ I am grateful to an anonymous referee for drawing my attention to this matter.
} 
Dialectica, Vol. 72, 2018, pp. 69-100.

result in alternative sets of desires ${ }_{R}$ that contain different instrumental desires $s_{R}$. Moreover, such a process could result in alternative sets of desires ${ }_{R}$ that contain different final desires ${ }_{R} .{ }^{21}$ Accordingly, it is plausible to think that $S$ is rationally required to have final desires $S_{R}$ and instrumental desires $R_{R}$ which are members of merely one such set of desires ${ }_{R} \cdot{ }^{22}{ }^{23}$ In other words, $\mathrm{S}$ is not rationally required to have desires $\mathrm{S}_{\mathrm{R}}$ that are members of every alternative set or an intersection of these alternative sets. As a result, final and instrumental desires $_{R}$ that $S$ is rationally required to have can be considered to belong to the same set of desires ${ }_{R}$. In what follows, I will be concerned with final and instrumental desires $_{R}$ within one single set of desires $_{R}$ of this type.

It is also expedient in this context to make a distinction between two different types of means in relation to $S^{\prime}$ s final desires. A necessary means for the satisfaction of a certain final desire $_{R}$ is such that if it does not come into being, it would be impossible for $S^{\prime}$ s final desire ${ }_{R}$ to be satisfied. A non-necessary means for the satisfaction of a certain final desire $e_{R}$ is such that even if it does not come into being, $S^{\prime}$ s final desire ${ }_{R}$ can be satisfied by some other means.

\section{Rationally Required and Justified Desires in terms Desires $_{R}$}

It is now time to take a closer look at the connection between the notion of rationality and the notion of desires $S_{R}$. According to subjectivism, an agent $S$ would have a set of desires $s_{R}$ if she were to go through a process of informed rational deliberation which starts off in her actual desires. In what follows, I will argue that claims about what desires $S$ is rationally required and rationally justified in having can be explicated in terms of how they are related to such a set of desires $_{R}$. However, I will contend that there is no simple mapping between these notions. Specifically, it is not the case that $S$ is rationally required to have every desire $e_{R}$ which is member of such a set of desires ${ }_{\mathrm{R}}{ }^{24}$ Moreover, $\mathrm{S}$ might be rationally justified to have a desire to $\phi$ even if it would not be member of any set of desires. The upshot is a picture of the connection between rationality and desires that, in my view, is more in agreement with our common sense conception of rationality than alternative formulations of subjectivism.

\footnotetext{
${ }^{21}$ The first possibility rests on the plausible assumption that there might be a number of different instrumental desires $_{R}$ for means which fulfil the same final desire $E_{R}$ equally well. The second possibility should also be taken seriously. For example, assume that the mentioned type of process involves 'systematic justification of desires'. It might be possible that there are several general, final, desires $S_{R}$ which explain and vindicate more specific desires equally well.

${ }^{22}$ Moreover, as I will argue below, $\mathrm{S}$ is not rationally required to have every desire $\mathrm{R}_{\mathrm{R}}$ that is member of such a set.

${ }^{23}$ The mentioned possibility raises the further question whether $S$ is rationally justified to have desires which are members of more than one set of desires $_{R}$ in case these sets contain different desires. In the present paper, I will not discuss this issue since it is not significant to my argument. However, it might be observed that if this is the case, there would be a wider source of rationally justifying reasons than I consider in the text. I am grateful to an anonymous referee to pointing this out.

${ }^{24}$ That is, $S$ is not even rationally required to have every desire ${ }_{R}$ that is member of a set of desires $s_{R}$ of the type detailed above.
} 
Dialectica, Vol. 72, 2018, pp. 69-100.

It should be uncontroversial to maintain that, in a central sense of 'rational', to claim that an agent $S$ is rational entails that she is practically well-functioning in a certain respect. Conversely, to claim that she is irrational entails that she is practically malfunctioning in a certain respect. It should be equally uncontroversial to maintain that if $S$ is irrational, it is legitimate to direct criticism against her for failing cognitively in a certain regard, what might be called 'rational criticism' ${ }^{25}$ In what follows, I would like to distinguish between three types of connections between rationality and desires ${ }_{R}$ which might hold on subjectivism.

First, according to subjectivism it is plausible to think that an agent $\mathrm{S}$ is rationally required to have a desire to $\phi$ insofar as $\phi i n g$ is a necessary means to satisfy a final desire $e_{R}$ which is part of a set of desires $_{R}$ in the way specified above. To illustrate, assume that $S$ has a final desire $e_{R}$ to lead a happy life and that a necessary means to satisfy this desire is that she gets some friends. As indicated above, the objects of $S^{\prime} S$ final desires ${ }_{R}$ constitute what are absolutely most important to her. It then seems reasonable to think that it would be irrational for $\mathrm{S}$ to lack a desire to get some friends, since this would result in it being impossible for her to attain something she ultimately strives for. Accordingly, it seems reasonable to assume that $\mathrm{S}$ would be practically malfunctioning and open to criticism for failing cognitively were she to lack such a desire. Consequently, S might have a requiring reason to $\phi$ in virtue of $\phi i n g$ being a necessary means to satisfy any of her final desires ${ }_{R}$.

Second, according to subjectivism it is plausible to think that an agent $\mathrm{S}$ is rationally justified, but not rationally required, to have a desire corresponding to each particular nonnecessary means to satisfy a final desire $\mathrm{R}_{\mathrm{R}}$. It would be irrational for $S$ to lack a desire for a necessary means to satisfy a final desire ${ }_{R}$. However, for each such necessary means there are various non-necessary means to satisfy the final desire $e_{R}$ in question. First, each individual nonnecessary means is such that even if it does not come into being, $S$ can have her final desire $e_{R}$ satisfied. Second, there are innumerable non-necessary means of this kind. In view of this, it does not seem irrational for $S$ to lack a desire for each non-necessary means to satisfy a final desire $_{R}{ }^{26}{ }^{6}$ However, it does not seem irrational for $\mathrm{S}$ to have a desire for each, or at least many, non-necessary means for the satisfaction of one her final desires ${ }_{R}$. After all, each of the nonnecessary means is an alternative means to satisfy one of $S^{\prime} S$ final desires ${ }_{R}$. In the example above, there might be alternative non-necessary means for $\mathrm{S}$ to attain the necessary means to get some friends, such as inviting people to dinner or helping them to move or looking after their children, etc. In that case, it would normally not be irrational for $\mathrm{S}$ to have a desire to

\footnotetext{
${ }^{25}$ See e.g. Gert (2004, 143); Parfit (2011, 33); Ridge (2014, Ch. 8); Kiesewetter (2017, Ch. 2), and Wedgwood (2017, Ch. 6). I defend this notion in more detail in Strandberg $(2017,63-88)$.

${ }^{26}$ This provides an explanation of some cases in which actions are rationally justified without being rationally required. For an alternative account that is intended to be completely general, see Portmore $(2011, \mathrm{Ch} .6)$.
} 
Dialectica, Vol. 72, 2018, pp. 69-100.

invite people to dinner and a desire to help them to move, etc. Consequently, it might be argued that $S$ has a justifying reason to $\phi$ in virtue of $\phi i n g$ being a non-necessary means to satisfy any of her final desires . $_{\text {. }}$

Third, and most importantly, subjectivism is compatible with an agent $\mathrm{S}$ being rationally justified in having a desire $\phi$ even if $\phi i n g$ does not serve the satisfaction of any of her desires $R_{R}$ given that ping has some other feature which rationalizes her desire to $\phi$. Moreover, this feature might be an external feature of ping. An 'external feature' of $\mathrm{S}^{\prime} \mathrm{S}$ action can be understood as a feature which does not involve any reference to her desires (actual desires or desires $_{R}$ ). To illustrate, assume that $S$ is in the position to help another agent $T$ but that doing so would not serve to satisfy any of S's own desires, but would be of great importance to T. For example, suppose that $\mathrm{T}$ has been involved in a serious car accident and that $\mathrm{S}$ can relieve his grave pain by getting him to the hospital. Intuitively, it would presumably not be irrational for $\mathrm{S}$ to have a desire to help $\mathrm{T}$ in consideration of what she can do for him, although she is not necessarily irrational if she lacks it. It seems plausible to think that $S$ need not be practically malfunctioning in case she has a desire to help $T$, which means that she need not fail cognitively in a way that justifies directing the relevant type of criticism against her. However, it would be irrational, or non-rational, for $S$ to have a desire to perform the action on no grounds at all. Accordingly, the action needs to have some external feature which rationalizes a desire to perform it. For example, the action might be such that it serves to satisfy some of $T^{\prime}{ }^{\prime}$ desires $_{R}$, e.g. a final desire $\mathrm{R}_{\mathrm{R}}$ to avoid pain. Consequently, on this line of argument $\mathrm{S}$ might have a justifying reason to $\phi$ in virtue of $\phi i n g$ having a certain external feature.

Let us consider in more detail why this possibility is compatible with subjectivism. It should first be pointed out, however, that on this view requiring reasons cannot be based on external features. An agent $S$ has a requiring reason to $\phi$ insofar as she is rationally required to have a desire to $\phi$, in which case she would be irrational if she lacks the desire in question. According to subjectivism, $\mathrm{S}$ is rational in the relevant respect insofar as she has a set of desires $_{R}$. In particular, it is irrational for $S$ to lack a desire to $\phi$ only if it is member of a set of this type. Thus, the fact that фing has a certain external feature, which by definition does not make any reference to $S^{\prime} S$ desires $S_{R}$, cannot give rise to a requiring reason for her to $\phi$.

However, justifying reasons can be based on external features according to subjectivism. An agent $\mathrm{S}$ has a justifying reason to $\phi$ insofar as it would be rationally justified for her to have a desire to $\phi$. In order not to beg any questions, let us understand subjectivism strictly so as to comprise both necessary and sufficient conditions for the relevant aspect of rationality. First, assume that $S$ having a set of desires $_{R}$ constitutes a necessary condition for her being rational in the relevant respect. $A$ set of desires $S_{R}$ is a set of desires $S$ would have 
Dialectica, Vol. 72, 2018, pp. 69-100.

were she to go through a process of informed rational deliberation which takes its starting point in her actual desires. This condition is compatible with it being rationally justified for $\mathrm{S}$ to have some further desires which might not be derivable from her actual desires in this manner, given that there is some other ground which ensures that it would be rationally justified for her to have such a desire. In particular, ding might have a certain external feature which makes it rationally justified for $\mathrm{S}$ to have a desire to $\phi$, even if this desire would not be part of a set of desires ${ }_{R}$. Second, assume that $S$ having a set of desires $s_{R}$ constitutes a sufficient condition for her being rational in the relevant respect. This condition is also compatible with it being rationally justified for $\mathrm{S}$ to have some further desires. In particular, there might be a ground, in the form of an external feature, which makes her rationally justified in having a desire to $\phi$, even if this desire would not be part of a set of desires ${ }_{R}$.

As far as I understand, this possibility is not at variance with the spirit of subjectivism. First, it is compatible with subjectivism providing both necessary and sufficient conditions of the relevant aspect of rationality in terms of desires $_{R}$. What I have said so far merely suggests that if $S^{\prime} S$ desire to $\phi$ is not made rational by ping serving to satisfy any of her desires, it can be made rational in some other way, viz. by some external feature. Second, I have argued that it is compatible with subjectivism that $S$ might be rationally justified in having such a desire to $\phi$, given that $\phi i n g$ has some external feature which explains why this is the case. Subjectivists might however argue that there in fact is no external feature which fulfils this function. Although subjectivism is formally compatible with the possibility of this type a feature giving rise to justifying reasons, it might perhaps be worried that an external feature would be added onto subjectivism in a mere ad hoc manner. However, in Section 10 I will outline a suggestion of an external feature which represents a natural development of subjectivism. Lastly, it might perhaps be objected that $\mathrm{S}$ having desires that are rationally authorized in different manners would be incompatible with her being rational, since it means that she might have fundamentally conflicting desires, i.e. a desire to $\phi$ and a desire not to $\phi$. However, it is uncontroversial that a rational agent might have a pro tanto reason to $\phi$ and a pro tanto reason not to $\phi$, and have desires corresponding to these reasons. Consequently, it is generally accepted that a rational agent can have fundamentally conflicting desires of this type. ${ }^{27}$

It should be emphasized that suggesting that justifying reasons can be based on external features does not presume objectivism about rationality. According to objectivism, S's

\footnotetext{
${ }^{27}$ See e.g. Marino (2010, 232-234). It might perhaps be worried that it would be irrational to have underived desires which are in fundamental conflict. However, in the case under consideration these desires would concern different features of an action: an underived desire to $\phi$ in virtue of a certain feature of $\phi i n g$ and an underived desire not to $\phi$ in virtue of some other feature of $\phi i n g$. It is difficult to see that it would be irrational to have fundamentally conflicting desires which have different objects. Cf. Marino (2009, 277-281).
} 
Dialectica, Vol. 72, 2018, pp. 69-100.

rationality is understood in terms of her having certain particular desires which are entirely independent of her actual desires. Thus, on most versions of this view $\mathrm{S}$ is rationally required to have a desire of this kind, in which case she would be irrational if she lacks it. However, $\mathrm{S}$ has a justifying reason to $\phi$ insofar as she is rationally justified to have a desire to $\phi$, in which case she is not irrational if she lacks it. Thus, $\mathrm{S}$ having a justifying reason to $\phi$ which is based on an external feature of $\phi i n g$ does not presume objectivism.

To sum up, in this section we have found ways of specifying (R) and (J) which in turn provide characterizations of 'feature $F^{\prime}$ ' in these claims. First, (R) can be specified as follows:

(S1) (i) It would be irrational for an agent $S$ to lack a desire to $\phi$ if $\phi$ ing is a necessary means to satisfy any of her final desires $s_{R}$. (ii) It would not be irrational for $S$ to lack a desire to $\phi$ if this is not the case. ${ }^{28}$

Second, (J) can be specified as follows:

(S2) (i) It would not be irrational for an agent $\mathrm{S}$ to have a desire to $\phi$ if (a) фing has an external feature which rationalizes her desire to $\phi$, or (b) ping is a non-necessary means to satisfy any of $S^{\prime}$ s final desires ${ }_{R}{ }^{29}$ (ii) It would be irrational, or non-rational, for $S$ to have a desire to $\phi$ if (a) or (b) is not the case. ${ }^{30}$

In Section 10, I will suggest an instance of (S2) that specifies a 'feature $F^{\prime}$ in the form of an external feature which can give rise to categorical moral reasons. ${ }^{31}$

\section{The Sources and Significance of Reasons}

Let us take stock. An agent $S$ has a requiring reason to $\phi$ insofar as фing has a feature $F$ which makes it rationally required for her to have a desire to $\phi$. According to subjectivism, it is plausible to think that $\mathrm{F}$ consists in ping being such that it is a necessary means for satisfying

\footnotetext{
${ }^{28}$ Again (ii) holds ceteris paribus. That is, it holds unless $\phi i n g$ has some other feature $F^{\prime}$ which has this function.

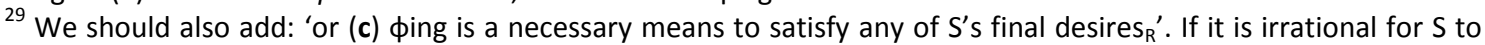
lack a desire to $\phi$, it cannot be irrational for her to have a desire to $\phi$. As I use 'rationalize', an external feature rationalizing a desire to $\phi$ entails that it explains why it is rationally justified to have a desire to $\phi$ in the sense

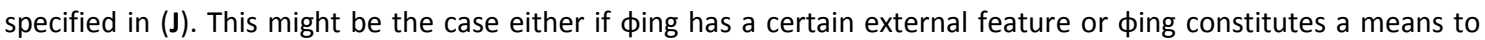
realize a state of affairs which has such a feature. I will ignore this complication since it does not affect my argument.

${ }^{30}$ Again (ii) holds ceteris paribus. That is, it holds unless фing has some other feature $F^{\prime}$ which has this function.

${ }^{31}$ According to an influential argument, views stating that reasons are based on idealized desires are vulnerable to 'the conditional fallacy' (Johnson (1999, 53-71)). Michael Smith suggests that this objection can be avoided if the example model is exchanged for the advice model (Smith $(1995,109-131)$ ). However, ER is not vulnerable to this argument, since it understands the relevant subclass of $S^{\prime}$ s reasons in terms of means to satisfy her final desires $s_{R}$, rather than in terms of a complete set of desires ${ }_{R}$. For instance, in Smith's squash example the hot tempered loser does not have any reason to cross the court to shake hands with her opponent, since doing so would not constitute a means to satisfy any of her final desires. (It would end with her smashing her opponent in the face.) By contrast, she has reason to politely leave the court, since doing so would constitute a means to satisfy a final desire ${ }_{R}$ of hers. (It would mean that she still can be friends with her opponent.) Cf. Gert (2002, 88-95).
} 
Dialectica, Vol. 72, 2018, pp. 69-100.

any of her final desires. An agent $S$ has a justifying reason to $\phi$ insofar as $\phi i n g$ has a feature $F$ which makes it rationally justified for her to have a desire to $\phi$. According to subjectivism, $F$ might consist in ping being such that it is a non-necessary means for satisfying any of her final desires $_{R}$. Most importantly, subjectivism is compatible with $\mathrm{F}$ consisting in an external feature of $\phi i n g$. Thus, on $E R$ reasons have two sources: desires $_{R}$ and external features.

It might be thought that requiring reasons need to have more weight than justifying reasons due to their different relations to rationality. This is a complex issue that would require a lengthy discussion that I cannot pursue in this paper. It should be observed, however, that $E R$ is compatible with various possibilities as regards the weight of reasons. Let me mention two. First, it is compatible with the view that requiring reasons and justifying reasons are incommensurable. This would make $E R$ consonant with the familiar contention that moral and self-interested reasons cannot (always) be compared, an idea that has plausibility regardless of the distinction between requiring and justifying reasons. ${ }^{32}$ Second, and most importantly, as Gert argues there are grounds to question the assumption that there is a direct correspondence between the weight of reasons and rationality. It seems possible to imagine situations in which S has a significant reason to $\phi$ and a less significant reason to $\psi$, but where she is not rationally required to $\phi$ rather than to $\psi$. For example, $S$ might have a significant moral reason to help T who is in need, and a less significant reason to avoid doing so because it would cause herself some discomfort, but it is not evident that she would be irrational in performing the latter action rather than the former. ${ }^{33}$ In Gert's view, we should avoid considering requiring and justifying reasons as necessarily differing in weight because of their different connections to rationality. As Gert writes, "[it] is not even reliably the case that, in conflicts of two reasons, one ought to act on the reason that has the greatest requiring strength. For the opposing reason may well have sufficient justifying strength to make it rationally permissible to act on it instead". ${ }^{34}$ This means that a justifying reason might be more significant than a requiring reason in a certain respect. Applied to $E R$, it means that $\mathrm{S}$ might have a categorical moral reason, in the form of a justifying reason based on an external feature, to $\phi$ which in a certain respect is more significant than a conflicting reason, in the form of a requiring reason based on her desires $_{R}$, to $\psi$. For example, $S$ might have a moral reason, in the form of a justifying reason, to help T which is more significant than her reason, in the form of a requiring reason, not to do so. As a result, $S$ is rationally justified, but not rationally required, to perform the former action rather than the latter.

\footnotetext{
32 See e.g. Copp (1997, 86-106); Tiffany (2011, 231-262), and Sagdahl (2014, 405-425). Cf. Raz (1999, Ch. 5) and Parfit (2011, Ch. 6). For criticism, see Chang (2012, 106-126).

${ }^{33}$ Gert (2004, 22-23, 36-38, 88-92). Gert (2007, 532-562). Cf. Sidgwick (1981, Book IV).

${ }^{34}$ Gert $(2007,561)$.
} 
Dialectica, Vol. 72, 2018, pp. 69-100.

It might be objected that on internalism determining the weight of reasons is more straightforward than on $E R$, since the former view implies that this notion can be described simply by referring to the varying strengths of rational desires. However, this is a worry that also afflicts sophisticated 'Neo-Humean' views about reasons which attempt to accommodate the proper weight of various reasons. ${ }^{35}$ More importantly, in Section 10 I will suggest that $E R$ is compatible with understanding the significance of reasons in terms of the strengths of agents' desires $_{R}$, although we should not understand rationality in this manner.

\section{Accounting for Differences in Rational Commitments}

In Section 3, I mentioned that we seem to have different conceptions of our rational commitments to ourselves and to others. We can now see that $E R$ is able to accommodate this contention.

First, $E R$ can account for the notion that what an agent $S$ is rationally required to do typically concerns what is of most importance to herself, such as her own basic-well-being. On this view, $S$ is rationally required to have a desire to $\phi$ insofar as $\phi i n g$ is a necessary means to satisfy any of her final desires $R_{R}$. It is plausible to assume that we generally have final desires $_{R}$ concerning our own basic well-being. To illustrate, assume that $\mathrm{S}$ suffers severe pain and that there is a medicine which would cure it. It seems plausible to think that she is rationally required to have a desire to get the medicine, since it presumably constitutes a necessary means to satisfy a final desire ${ }_{R}$, e.g. a desire to avoid pain. Second, $E R$ can account for the notion that what $S$ is rationally justified, but not rationally required, to desire typically concerns the well-being of others. On this view, $\mathrm{S}$ is rationally justified to have a desire to $\phi$ insofar as фing has an external feature, which might concern the well-being of others. Assume that $S$ could help $T$ who is in serious pain by getting him a certain medicine. For the reasons suggested above, it does not seem that $S$ is rationally required to have a desire to help $T$; nonetheless, it seems that she is rationally justified to have such a desire.

Thus, $E R$ can accommodate the notion that we have different conceptions of our rational commitments to ourselves and to others. Moreover, it is possible to argue that $E R$ is more flexible than Gert's account in a certain respect. On the one hand, Gert's view understands what an agent $\mathrm{S}$ is rationally required to do in terms of a substantive objectivist notion of rationality. This view entails that $S$ is rationally required to $\phi$ insofar as $\phi i n g$ is essential to secure her basic well-being, given that there are no other considerations with enough justifying strength to make it rationally permissible for her not to $\phi$. On the other

\footnotetext{
${ }^{35}$ Cf. Schroeder (2007, Ch. 7). See also Gert (2004, Ch. 5).
} 
Dialectica, Vol. 72, 2018, pp. 69-100.

hand, $E R$ understands what $S$ is rationally required to desire in terms of subjectivism about rationality, which suggests that she is rationally required to have a desire to $\phi$ insofar as фing is a necessary means to satisfy any of her final desires ${ }_{R}$. This view is able to capture much of what is attractive in Gert's view. On the plausible assumption that we generally have final desires $_{R}$ concerning our own basic well-being, $E R$ entails that we would be irrational unless we desire what is needed to secure it. However, this view has the further advantage of leaving open the possibility that $S$ might be rationally required to have a desire to $\phi$ even if $\phi i n g$ does not have any immediate consequences for her own well-being. To illustrate, assume that $\mathrm{S}$ has dedicated her entire life to help others and that she has a final desire ${ }_{R}$ to improve other people's well-being. If so, $\mathrm{S}$ might be rationally required to have a desire to help $\mathrm{T}$, given that doing so is necessary to satisfy this final desire ${ }_{R}$, although, intuitively, this would not affect her own well-being. More generally, ER entails the plausible view that $\mathrm{S}$ might be rationally required to have a desire to $\phi$ if $\phi i n g$ concerns what is of the absolute most importance to her, irrespective of whether ping affects her own well-being or not.

\section{The Fundamental Challenge}

As was pointed out earlier, theories about reasons face the basic challenge of accounting for the duality of their subject matter: some reasons seem to depend on, and vary with, desires whereas some reasons seem to be categorical. In contrast to internalism and externalism, $E R$ is able to accommodate his duality.

A central problem for internalism is that it is at variance with the basic notion that moral reasons are categorical. As I understand the concept of categorical reasons, it entails the following: If an agent $S$ has a categorical reason to $\phi$, then she has a reason to $\phi$ irrespective of whether she has any desire (actual desire or desire ${ }_{R}$ ) to $\phi$. For instance, $S$ has a reason to help $T$ irrespective of whether she has a desire to perform this action or would have such a desire in idealized conditions. According to internalism, whether $\mathrm{S}$ has a reason to $\phi$ depends on, and varies with, her actual desires. Hence, it is difficult to see that this view can account for the categoricity of moral reasons. ${ }^{36}$

Traditional versions of externalism face the reverse problem. Many of our everyday reasons seem to be contingent on our actual desires. To take a trivial example, assume that $S$ desires an ice cream while $\mathrm{T}$ does not. It then seems plausible to think that, ceteris paribus, $\mathrm{S}$ has a reason to get an ice cream whereas $\mathrm{T}$ does not, or at least that $\mathrm{S}$ has a stronger reason to

\footnotetext{
${ }^{36}$ For a detailed explanation of why internalism is unable to account for the conceptual core of ethics, see Lillehammer (1999b, 117-133). As before, 'actual desires' refer to the desires $\mathrm{S}$ has before she has gone through a process of informed rational deliberation.
} 
Dialectica, Vol. 72, 2018, pp. 69-100.

get one than $\mathrm{T}^{37}$ According to externalism, whether $\mathrm{S}$ has a reason to $\phi$ does not directly depend on, or vary with, her desires. Thus, it might be worried that this view has difficulties to account for the difference between S's and T's reasons. ${ }^{38}$ Externalists might respond that the fact that $\mathrm{S}$ desires an ice cream, whereas $\mathrm{T}$ does not, makes $\mathrm{S}$, say, enjoy it more than $\mathrm{T}$, which explains the difference. ${ }^{39}$ In reply, the fact that $S$ desires an ice cream, whereas $T$ does not, seems at least to give $S$ a stronger reason to get one, irrespective of her enjoying it more than T. This kind of consideration becomes especially plausible in cases of tie-breaking (see Section 9).

\section{Categorical Moral Reasons}

According to $E R$, an agent $S$ might have a justifying reason to $\phi$ in virtue of $\phi i n g$ having an external feature of $\phi i n g$, i.e. a feature not making any reference to her desires (actual desires or desires ${ }_{R}$ ). Hence, this view leaves open the possibility that $S$ has a categorical moral reason, in the form of a justifying reason, to $\phi$ in virtue of $\phi i n g$ having such a feature, since she would have this reason irrespective of whether she has any actual desire or desire $e_{R}$ to $\phi$.

It might be objected that although $E R$ allows that there are categorical reasons in the basic sense mentioned above, it is incompatible with there being categorical reasons in a stronger sense: If an agent $S$ has a categorical reason to $\phi$, then (i) she has a reason to $\phi$ irrespective of whether she has any actual desire or desire $e_{R}$ to $\phi$, and (ii) she is rationally required to have a desire to $\phi$.

However, this objection rests on the assumption that moral reasons consist in requiring reasons. First, I have suggested that moral reasons might consist in justifying reasons rather than requiring reasons: If $S$ has a moral reason to $\phi$, she is not rationally required, but rather rationally justified, to have a desire to $\phi$. Importantly, this means that moral reasons are not like mere conventional reasons which do not have either of these connections to rationality. Second, the objection ignores Gert's essential point that our rational commitments to ourselves and to others seem to differ. Third, it should be recalled that moral reasons constituting justifying reasons rather than requiring reasons need not have any straightforward implications concerning the weight of reasons. Especially, S might have a categorical moral reason, in the form of a justifying reason, to $\phi$ which is more significant than a conflicting reason, in the form of a requiring reason, to $\psi$. Lastly, S might have a categorical moral reason, in the form of a justifying reason, to $\phi$ as well as an additional reason, in the

\footnotetext{
${ }^{37}$ See e.g. Finlay and Schroeder (2017, 20-21). Cf. Chang (2004, 56-90).

${ }^{38}$ Cf. Schroeder (2007, Ch. 4). For criticism, see Gert (2009a, 325-329).

${ }^{39}$ See e.g. Parfit $(2011,67-70)$.
} 
Dialectica, Vol. 72, 2018, pp. 69-100.

form of a requiring reason, to $\phi$. For example, $\mathrm{S}$ might have the first type of reason to help $\mathrm{T}$ because the action has a certain external feature, and the second type of reason to help $T$ because, say, it is the only way for her to avoid unpleasant reactions from others. In other words, $\mathrm{S}$ might have both a justifying reason and a requiring reason to act morally.

\section{Desire-Based Reasons}

According to $E R$, both requiring and justifying reasons might be based on desires $s_{R}$. As a result, the view is able to account for the notion that agents might have different reasons because they differ in their actual desires. To simplify, let me illustrate this in terms of justifying reasons. Assume that $S$ desires an ice cream while $T$ does not and that $S^{\prime}$ ' desire is a desire $e_{R}$. In that case, it presumably constitutes a desire ${ }_{R}$ for a non-necessary means to satisfy any of her final desires $R_{R}$ e.g. a desire to have a certain type of pleasurable experience. This means that $S$ has a justifying reason to get an ice cream in virtue of having such a desire ${ }_{R}$. Presumably, the same cannot be said about $\mathrm{T}$. It is worth observing that $E R$ is compatible with the possibility that $\mathrm{T}$ has a justifying reason to get an ice cream in virtue of this having some external feature. Nevertheless, it seems plausible to think that $\mathrm{S}$ has a more significant justifying reason to get an ice cream than $T$, due to the fact that $S$ has a desire $e_{R}$ to have one whereas $T$ does not.

A common objection to internalism is that this view implies that agents do not have any categorical self-interested or prudential reasons. A similar objection might be directed against $E R$. According to this worry, $\mathrm{S}$ might have a self-interested reason to $\phi$ irrespective of whether she would have any desire $e_{R}$ to $\phi$. The most influential version of this type of argument maintains that $S$ has a reason to avoid pain even if she would not have any desire $e_{R}$ to this effect, i.e. even if she would not have such a desire were she to go through a process of informed rational deliberation. ${ }^{40}$

The present objection deserves a more thorough discussion than I can provide in this paper, but I think it can be responded to in five steps which successively reduce its force. First step. It should be pointed out that $E R$ has the same resources as internalism to counter this type of worry. It might be argued that the objection rests on a failure to recognize the force of the rational considerations involved in the relevant type of deliberative process. More precisely, on this response these considerations ensure that $S$ would have a desire to avoid pain were she to go through such a process. If this is correct, she might be rationally required

\footnotetext{
${ }^{40}$ See e.g. Parfit (2011, Ch. 3 and 4). For responses, see e.g. Goldman (2009, Ch. 4); Shemmer (2007, 326-348), and Sobel $(2011,52-78)$. Intuitively, a 'self-interested reason' is a reason which concerns what is good or bad for a single individual.
} 
Dialectica, Vol. 72, 2018, pp. 69-100.

to have a desire to avoid pain. In that case, $\mathrm{S}$ would have a requiring reason to do so. ${ }^{41}$ However, assume for the sake of the argument that this response is unsuccessful. Second step. It might be maintained that there are no categorical self-interested reasons, either in the form of requiring or justifying reasons. Arguments to the effect that $S$ might have a self-interested reason to $\phi$ irrespective of whether she would have any desire ${ }_{R}$ to $\phi$ standardly appeal to reasons with regard to having or lacking certain types of experiences, especially pain. The explanation is presumably that, intuitively, $\mathrm{S}$ has a reason to avoid pain in virtue of the intrinsic character of this experience, irrespective of what else is true of her. Thus, it is assumed that she has a reason to avoid pain irrespective of whether she would have any desire $e_{R}$ to this effect. It is plausible to doubt, however, that $S$ has a reason to avoid a certain type of experience if she has nothing against being in that state; that is, if she does not dislike having the experience or would not dislike having it in idealized conditions. Now, 'dislike' refers presumably to a type of basic desire. Consequently, $\mathrm{S}$ has a reason to avoid pain only if she has a relevant desire not to have that type of experience. ${ }^{42}$ It follows that she does not have a categorical reason to avoid pain. However, assume for the sake of argument that there might be categorical self-interested reasons. Third step. It might be doubted that this provides any support to the claim that there are categorical self-interested reasons in the form of requiring reasons. An agent $S$ has a requiring reason to $\phi$ insofar as she is rationally required to have a desire to $\phi$, in which case she would be irrational if she lacks the desire in question. However, the type of argument under consideration standardly appeals to intuitions about reasons rather than intuitions about rationality. ${ }^{43}$ As far as I understand, the objection is that $\mathrm{S}$ might have a reason to, say, avoid pain even if she would not have any desire $e_{R}$ to do so, not that she would be irrational if she lacks a desire to avoid pain. In particular, if $\mathrm{S}$ does not dislike being in pain, it does not seem that she is rationally required to have a desire to avoid this experience. Fourth step. There are grounds to deny that there are any categorical self-interested reasons in the form of requiring reasons. As indicated earlier, in a central sense of 'irrational', to claim that $\mathrm{S}$ is irrational in lacking a desire to avoid pain entails that she is practically malfunctioning in a way which makes it justified to criticize her for failing cognitively in a certain respect. Assume that $\mathrm{S}$ is rational in the fundamental sense of having the capacity to pursue a process of rational deliberation. The objection under consideration then entails that, to be fully rational, $\mathrm{S}$ needs to have a desire to avoid pain even if there is no such process which would

\footnotetext{
${ }^{41}$ According to a related objection, $\mathrm{S}$ need not have any desire to avoid future misfortunes. In a response, Michael Smith argues that a rational agent has desires $s_{R}$ which concern her future, e.g. a desire ${ }_{R}$ to avoid future pain (Smith $(2009,98-125))$. For another type of solution, see Sobel (2011, 52-78).

${ }^{42}$ Cf. Sobel (2011, 55-60).

${ }^{43}$ See e.g. Shafer-Landau (2003, 185-187); Finlay and Schroeder (2017, 18-20), and Parfit (2011, Ch. 3 and 4). Cf. Quinn $(1993,228-255)$ and Bedke $(2010,40)$. But see also Gert $(2004,55,174-175)$.
} 
Dialectica, Vol. 72, 2018, pp. 69-100.

make her acquire it. However, in that case it seems unfair to direct the mentioned type of criticism against her, since there is virtually nothing she can do to improve with regard to rationality so as to acquire the desire in question. ${ }^{44}$ This suggests that $S$ does not have a categorical reason, in the form of a requiring reason, to avoid pain. Fifth step. According to ER, there might be categorical self-interested reasons in the form justifying reasons. Thus, $\mathrm{S}$ might have a reason of this type to avoid pain in virtue of the action having a certain external feature. Avoiding pain might, for example, improve her well-being where 'well-being' is not taken to make any reference to her desires ${ }_{R}$. In this regard, $E R$ has an advantage over internalism, since the latter view implies that $S$ cannot have any categorical reasons whatsoever.

Another common objection to internalism is that it implies that agents have reasons that we intuitively do not want to ascribe to them. A similar objection might be directed against $E R$. For example, it might be worried that $\mathrm{S}$ has a reason to count the blades of grass or carry out some other meaningless activity given that she would have a desire ${ }_{\mathrm{R}}$ to do so.

Like the last worry, this deserves more discussion than I can provide in the present paper, especially since it calls for a thorough account of the rational considerations involved in the relevant type of deliberative process. However, once again I think it can be responded to in a series of steps that reduce its force. First step. It might be argued that a desire to perform the indicated type of action would not survive a process of informed rational deliberation. For example, it is difficult to see that it would constitute a desire for a means to satisfy any of her final desires $s_{R}$ in view of the pointlessness of the activity. Relatedly, recent research suggest that desires and other affective states form part of a systematic learning procedure in which they continually adjust to new information and challenges ${ }^{45}$ It is difficult to see how a desire of the mentioned type would constitute an aspect of such a procedure. Second step. It is possible to argue that $E R$ has particular resources to meet the objection under discussion, due to the fact that this view connects different types of reasons to different types of desires ${ }_{R}$. According to $E R, S$ has a requiring reason to $\phi$ only insofar as $\phi i n g$ is a necessary means to satisfy any of her final desires ${ }_{R}$. It is reasonable to assume that even if a desire of the mentioned type were to survive, it would not constitute a desire for a necessary means to satisfy a final desire ${ }_{R}$. One ground is that there are numerous alternative means to satisfy a given final desire $e_{R}$. For example, it is difficult to see that counting blades of grass would constitute a necessary means to satisfy a final desire $e_{R}$ to, say, have a certain pleasurable

\footnotetext{
${ }^{44}$ I develop this line of thought in Strandberg $(2017,63-88)$.

45 Railton $(2014,813-859)$. In a thorough discussion of this type of cases, Sharon Street argues that they do not provide convincing arguments against desire-based views of reasons (Street (2009, 273-298)).
} 
Dialectica, Vol. 72, 2018, pp. 69-100.

experience. Third step. It might be accepted that $\mathrm{S}$ has a justifying reasons to perform the action in question, albeit a very weak one. As is generally agreed, an agent might have numerous insignificant reasons which are outweighed by more significant reasons. According to $E R$, it is plausible to think that, ceteris paribus, a reason which is based on a stronger desire ${ }_{R}$ is more significant than one which is based on a weaker desire ${ }_{R}$. For example, it is reasonable to assume that $\mathrm{S}$ has a more significant justifying reason to do something other than to count blades of grass, in virtue of the former action constituting a non-necessary means to satisfy a stronger final desire ${ }_{R}$.

\section{Desires as Tie-Breakers}

A potential difficulty with externalism is, as indicated above, that it is unable to account for the notion that desires appear at least minimally relevant in that they can function as tie-breakers between conflicting reasons. Assume that an agent $S$ has a desire-independent reason to $\phi$ which is as significant as her desire-independent reason to $\psi$. However, assume further that фing would fulfil her desires to a greater extent than $\psi$ ing. In such a case, it seems plausible to

think that $S$ has a more significant reason to $\phi$ than to $\psi \cdot{ }^{46}$ It might be argued that externalists have difficulties accounting for this since they maintain that reasons do not directly depend on, or vary with, desires.

In view of the fact that $E R$ allows both for reasons based on external features and reasons based on desires $s_{R}$, there are grounds to think that it can avoid at least some aspects of this difficulty. Assume that $S$ has a justifying reason to $\phi$, based on an external feature of $\phi i n g$, which is as significant as her justifying reason to $\psi$, based on a certain external feature of $\psi$ ing. However, suppose that ping satisfies her desires $_{R}$ to a greater extent than $\psi$ ing does. According to $E R, S$ might have an additional reason, based on her desires $s_{R}$, to $\phi$ rather than to $\psi$. The additional reason could be a requiring or a justifying reason depending on whether фing constitutes a necessary or non-necessary means to satisfy her final desires ${ }_{R}$. Consequently, $\mathrm{S}$ might have a more significant reason to $\phi$ than to $\psi$. It is remains to be investigated, though, to what extent $E R$ can account for various types of tie-breaking.

\section{Categorical Moral Reasons and a Suggestion of an External Feature}

According to $E R$, an agent $\mathrm{S}$ might have a categorical moral reason, in the form of a justifying reason, to $\phi$ in virtue of ping having an external feature, and this is compatible with

\footnotetext{
${ }^{46}$ Cf. Chang (2004: 56-90).
} 
Dialectica, Vol. 72, 2018, pp. 69-100.

subjectivism about rationality. It is now time to consider what such an external feature might consist in on this view. ${ }^{47}$

It is worth emphasizing that subjectivism is compatible with different views about what constitutes an external feature. As far as subjectivism is concerned, the only formal constraint on such a feature is that it can make it rationally justified for $S$ to have desire to $\phi$ in a manner which it is compatible with this view. Thus, it might consists in an evaluative or non-evaluative property, a moral or non-moral property, a natural or non-natural property, a property that is reducible in non-normative terms or a property that is not thus reducible, etc. However, as indicated above an external feature should not consist in a feature which merely is attached to subjectivism in an ad hoc manner, but should constitute a reasonable progress of this view.

According to subjectivism, an agent $S$ is rationally required to have a certain desire only insofar as it is member of a set of desires ${ }_{R}$ of hers. We have seen that $S$ might be rationally justified to have a desire to $\phi$ which is not be member of such a set of desires $s_{R}$, given that $\phi i n g$ has an external feature which explain why this is the case. An external feature is a feature that does not make any reference to $S^{\prime}$ s actual desires or desires. ${ }_{R}$ Importantly, however, it might refer to another agent's desires $s_{R}$. It is reasonable to suggest that on subjectivism the following constitutes an external feature which might give rise to categorical moral reasons: фing being such that it serves the satisfaction of another agent's desires ${ }_{R}$. Thus, I suggest that an instance of (S2) can be read thus:

(i) It would not be irrational for an agent $S$ to have a desire to $\phi$ insofar as ping serves to satisfy any of another agent T's desires ${ }_{R}$. (ii) It would be irrational, or non-rational, for $S$ to have a desire to $\phi$ if this is not the case. ${ }^{48}$

Now, I think it can be argued that this proposal constitutes a reasonable development of subjectivism. In order to see this, we should take a closer look at what it entails as regards rational considerations. As was noticed earlier, on subjectivism there are certain rational considerations that provide support for $S$ having a set of desires $S_{R}$. In a process of informed rational deliberation, $\mathrm{S}$ applies these considerations to her actual desires, and as a result comes to have such a set. This view does not imply that it is optional from the perspective of rationality whether to employ a rational consideration or not. They are considerations with regard to rationality that provide support for $S$ having a set of desires ${ }_{R}$ irrespective of whether

\footnotetext{
${ }^{47}$ The external feature I will consider is intended to account for moral reasons that are purely other-regarding or altruistic. It is compatible with the view I defend that they merely represent a subclass of moral reasons. However, it is presumably these moral reasons that are most difficult to vindicate given subjectivism, which make them especially important for the present discussion.

48 Importantly, (ii) holds ceteris paribus. That is, it holds unless ping has some other feature which means that it would not be irrational, or non-rational, to have the desire in question.
} 
Dialectica, Vol. 72, 2018, pp. 69-100.

she applies them or not. However, were $S$ to submit her actual desires to these considerations in a process of informed rational deliberation, she is ensured to have such a set.

There are two important aspects I would like to draw attention to with regard to rational considerations. First, on subjectivism this type of consideration is standardly thought to provide support for a set of desires $\mathrm{R}_{\mathrm{R}}$ that $\mathrm{S}$ needs to have in order to be rational. That is, these rational considerations are thought to support a set of desires $_{R}$ she is rationally required to have. ${ }^{49}$ One uncontroversial rational consideration concerns means-end reasoning. In order to be rational, $\mathrm{S}$ needs to have desires for necessary means to satisfy her final desires. Another type of rational consideration concerns coherence among desires. One consideration of this type implies that $S^{\prime} S$ desires are to be coherent in such a way that more general desires explain and vindicate more specific desires. Second, on subjectivism it is standardly assumed that $\mathrm{S}$ is guaranteed to acquire a set of desires ${ }_{R}$ given that she applies these rational considerations to her actual desires in a process of informed rational deliberation. Especially, it is thought that she is guaranteed to acquire a set of desires $_{R}$ given that she goes through this type of a process, irrespective of what her actual desires consist in. We might formulate this in terms of 'input' and 'output'. An agent S supplies a certain set of actual desires as input, and if she goes through a process of informed rational deliberation in which she submits her actual desires to these rational considerations, then she would acquire a set of desires ${ }_{R}$ as output. As the output consists in a set of desires $s_{R}$ that she would acquire were she to go through such a process, she is guaranteed to acquire a set of desires of this type if she goes through the process, irrespective of what her actual desires consist in. ${ }^{50}$

Now, it is crucial to notice that subjectivism is compatible with two important possibilities which, as far as I understand, have not been explored in the debate. First, subjectivism is compatible with there being further rational considerations which do not provide support for any desires that $S$ is rationally required to have, but merely to desires that she is rationally justified to have. Moreover, such an additional consideration might concern coherence, although it would not support a desire she would be rationally required to have, but a desire she would be rationally justified to have. Second, it is compatible with subjectivism that such a rational consideration does not provide support for any desires that $\mathrm{S}$

\footnotetext{
${ }^{49}$ As mentioned in Section 5, we should leave open the possibility that such a process could result in various alternative sets of desires $R_{R}$. Accordingly, $S$ is rationally required to have merely one such set.

${ }^{50}$ The rational consideration as regards means-end reasoning presumably belongs to this type. The function of submitting her actual desires to means-end reasoning is not that $S$ is to acquire any particular desire. Rather, it is to ensure that she has desires for necessary means to satisfy her final desires. (However, see the comment on narrow vs. wide scope above.) Whatever her final desires consist in, employing this consideration will result in $\mathrm{S}$ acquiring instrumental desires for means that are required to satisfy her final desires. Thus, $\mathrm{S}$ is guaranteed to acquire a set of desires which includes desires for necessary means to satisfy her final desires, were she to go through a process of informed rational deliberation involving this consideration.
} 
Dialectica, Vol. 72, 2018, pp. 69-100.

is guaranteed to acquire were she to apply the consideration to her actual desires. Especially, whether she would be able to acquire a relevant desire by submitting her actual desires to this type of rational consideration might depend on the content of her actual desires. Again, we might formulate this in terms of 'input' and 'output'. An agent $S$ supplies a certain set of actual desires as input, and if she submits them to such a rational consideration, she might acquire a certain desire as output. Whether she would be able to acquire it by doing so depends on the input in the form of her actual desires. However, it is nevertheless the case that this consideration provides support for a desire it would be rationally justified for her to have. The idea is not that there are certain considerations $S$ needs to take into account and certain considerations which are optional from the perspective of rationality. Rather, the idea is the following: There are certain rational considerations which support desires that $S$ is rationally required to have and is guaranteed to acquire were she to submit her actual desires to them. However, it is possible that there is a further rational consideration which provides support for a certain desire but does not function in this manner. More precisely, even if S submits her actual desires to this consideration, it only supports a desire she is rationally justified to have, not a desire she is rationally required to have. And even if $\mathrm{S}$ submits her actual desires to this consideration, she is not guaranteed to acquire the desire in question. Whether she would acquire it or not might depend on the content of her actual desires.

We might now return to the above suggestion of an external feature. According to subjectivism, an agent $\mathrm{S}$ is rationally required to have a certain desire only insofar as it is part of a set of desires ${ }_{R}$ of hers, i.e. if it is a type of desire she would have were she to go through a process of informed rational deliberation which takes its point of departure in her actual desires. It can be argued, however, that there is a rational consideration which supports that $S$ is rationally justified to have a desire to $\phi$ where ping has the mentioned external feature: фing being such that it serves the satisfaction of any of another agent's desires $R_{R}$, i.e. a desire that agent would have were she to go through a process of informed rational deliberation which takes its starting point in her actual desires. Moreover, it can be argued that it consists of a further type of rational consideration with regard to coherence which might be captured by the notion 'treat similar cases alike'. It should be uncontroversial to maintain that there is a close connection between the notions of 'treat similar cases alike' and coherence, and between the notions of coherence and rationality. Thus, assume that $\mathrm{S}$ has a desire to $\phi$ where фing serves the satisfaction of another agent's desires. In that case, $\mathrm{S}$ would 'treat similar cases alike' in the sense that she treats another agent's desires ${ }_{R}$ in a way which is similar to the 
Dialectica, Vol. 72, 2018, pp. 69-100.

way she would treat her own desires ${ }_{R}{ }^{51}$ Accordingly, $S$ treats another agent's desires $s_{R}$ in a way which is coherent with how she would treat her own desires $s_{R}$, in which case it is plausible to think that she is rationally justified to have a desire to $\phi$, where фing has the mentioned external feature. ${ }^{52}$

We might make two observations in relation to the rational consideration I am trying to capture by the notion 'treat similar cases alike'. First, the claim is merely that it provides support for $\mathrm{S}$ having a desire to $\phi$, where $\phi i n g$ has the mentioned external feature, which she is rationally justified to have, not a desire she is rationally required to have. To start with, for the reason I suggested above it is plausible to think that this rational consideration provides support for $S$ being rationally justified to have a desire to $\phi$, where $\phi i n g$ serves to satisfy some of another agent's desires $R_{R}$. By contrast, this reason does nothing to establish that the consideration in question provides support for $\mathrm{S}$ being rationally required to have such a desire. Moreover, the claim is confirmed by the dialectic of the debate. There are efforts in ethics to demonstrate that it would be incoherent, and therefore irrational, for an agent to lack any concern for the satisfaction of other people's happiness, interests, or desires. ${ }^{53}$ However, it has turned out to be very difficult to establish such arguments. It might be hard to demonstrate that lacking such a concern would be incoherent in a way amounting to irrationality. In particular, it might be difficult to demonstrate that this would be a matter of outright irrationality by entailing practical malfunctioning and cognitive failure. Consequently, there are reasons to be pessimistic about the viability of this type of argument. Fortunately, the line of reasoning I suggest is much less demanding. It is not argued that lacking the mentioned desire to $\phi$ would be incoherent in a manner entailing irrationality, practical malfunctioning, and cognitive failure. Rather, it is suggested that it would be coherent, and thus rationally justified, to have the desire in question. It might be difficult to demonstrate that lacking such a desire to $\phi$ would be to fail to 'treat similar cases alike' in a way which would be incoherent by manifesting irrationality. However, it seems difficult to deny that having a desire to $\phi$ would be an instance of 'treating similar cases alike' in a manner that appears coherent and rationally justified. Furthermore, the claim is confirmed by the notion of irrationality $I$

\footnotetext{
${ }^{51}$ Moreover, if $S$ 'treats similar cases alike' by treating another agent $T$ 's desires $s_{R}$ in a way which is similar to the way

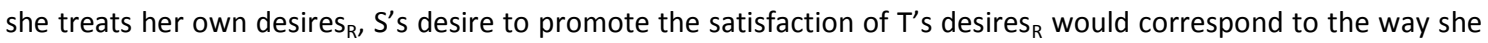
treats her own desires ${ }_{R}$ as regards whether they are final desires and how strong they are. That is, she prioritizes the satisfaction of necessary means to realize $T^{\prime}$ 's final desires $s_{R}$ and takes into consideration their strengths.

52 However, it might not be rationally justified for $S$ to have a desire to $\phi$ if $\phi i n g$ does not serve to satisfy any of another agent's desires .

53 See e.g. Hare (1981, Part II); Nagel (1970, Part 3); Smith (2012, 309-331), and Markovits (2014, Ch. 5). For alternative ways in which desires might 'improve' which are compatible with a procedural view of rationality, see Arruda (Forthcoming). For criticism of Markovits and Smith, see Sobel (2016, 531-538), and Bukoski (2016, 116146), respectively.
} 
Dialectica, Vol. 72, 2018, pp. 69-100.

appealed to earlier. ${ }^{54}$ In a central sense of 'irrational', to maintain that an agent $\mathrm{S}$ is irrational in lacking a certain desire entails that she is practically malfunctioning in a way which makes it warranted to criticize her for failing cognitively in a certain respect. Now, assume in line with what was argued above that $S$ would not be able to acquire the mentioned desire to $\phi$ even if she were to employ the rational consideration as regards 'treat similar cases alike'. There is, per hypothesis, no further rational consideration that she could employ so as to obtain the desire in question. In that case, there is virtually nothing she can do in terms of rationality to acquire it. As a result, it would seem unfair to claim that she is practically malfunctioning in a way which warrants rational criticism against her. Consequently, it would not be correct to insist that she has to be irrational in lacking the desire in question. It would thus be mistaken to insist that $S$ is rationally required to have a desire to $\phi$. However, as I stressed earlier, the consideration in question might still provide support for $\mathrm{S}$ having a desire to $\phi$. In particular, $\mathrm{S}$ might be rationally justified to have a desire to $\phi$. Second, the claim is merely that the rational consideration as regards 'treat similar cases alike' provides support for $\mathrm{S}$ having a desire to $\phi$, where фing has the mentioned external feature, not that she is guaranteed to acquire a desire to $\phi$ were she to submit her actual desires to this consideration. Whether $S$ is able to acquire a desire to $\phi$ by doing so might depend on the content of her actual desires which in turn displays her character. ${ }^{55}$ However, even if $S$ would not be able to acquire a desire to $\phi$ in this manner, the consideration provides support for her having the desire in question. ${ }^{56}$

Let us now briefly return to the issue of weighing reasons. In Section 6, it was suggested that a justifying reason might be more significant than a requiring reason in a certain sense. More precisely, $\mathrm{S}$ might have a categorical moral reason, in the form of a

\footnotetext{
${ }_{55}^{54}$ develop this argument in Strandberg (2017, 63-88). Cf. Lillehammer (2002, 47-62).

55 In contrast to means-end reasoning, the rational consideration as regards 'treat similar cases alike' does presumably not support a desire that $S$ is guaranteed to acquire. The function of applying this consideration to her actual desires is that $S$ is to have a certain particular desire: a desire to $\phi$, where $\phi i n g$ serves to satisfy any of another agent $T^{\prime}$ 's desires $s_{R}$. It is difficult to see that there could be any guarantee that $S$ acquires a desire to $\phi$ by employing this consideration, regardless of what her actual desires consist in. Whether she would be able to acquire it or not might depend on the content of her actual desires which in turn displays her character.

${ }^{56}$ According to this view, it would be rationally justified for $S$ to have a desire to $\phi$, where $\phi i n g$ promotes the satisfaction of $T^{\prime}$ 's desires ${ }_{R}$, in which case it need not be irrational for $S$ to lack such a desire. However, it might seem plausible to think that if $S$ does have a desire to promote the satisfaction of $T^{\prime} s$ desires $_{R}$, it would be irrational for $S$ to lack a desire to promote the satisfaction of another agent $U^{\prime} S$ desires $_{R}$ on the assumption T's and U's desires ${ }_{R}$ are identical in all relevant respects, and so on for all other agents. Unfortunately, this issue raises questions that I am not able to address in the present paper, which mainly is intended to provide an outline of the view. However, assume that this turns out to be correct. It might then be worried that $\mathrm{S}$ needs to treat everyone exactly equal and would not be allowed to pay special attention to her friends and family, etc. However, it seems plausible to think that this implication can be avoided. According to this alternative, an agent $S$ would have a desire to $\phi$ where $\phi i n g$ promotes the satisfaction of other people's desires ${ }_{R}$. It appears plausible to think that these people have desires which are sensitive to who the agents are of the various actions that influence them. To illustrate, it is plausible to assume that $S^{\prime}$ s mother has a desire $e_{R}$ to the effect that $S$, rather than some random person, takes care of her. This is a desire ${ }_{R}$ which only $S$ can satisfy. Hence, $S$ is allowed to care for her mother in a way she need not care for other people.
} 
Dialectica, Vol. 72, 2018, pp. 69-100.

justifying reason, to $\phi$ which in a certain respect is more significant than a conflicting reason, in the form of a requiring reason, to $\psi$. In such a case, $S$ would be rationally justified, but not rationally required, to $\phi$. Now, the above suggestion of an external feature provides a natural explanation of why this is possible in terms of the different strengths of agents' desires ${ }_{R}$. Assume that $\mathrm{S}$ has a categorical moral reason, in the form of a justifying reason, to help $\mathrm{T}$ in virtue of the action being a necessary means to satisfy one of T's strong final desires $s_{R}$ (say, to avoid a grave pain). However, assume further that $\mathrm{S}$ has a self-interested reason, in the form of a requiring reason, not to do so in virtue of this being a necessary means to satisfy any of her own weaker final desires $\mathrm{R}_{\mathrm{R}}$ (say, to avoid a minor discomfort). In consideration of the fact that $T^{\prime}{ }^{\prime}$ desire $_{R}$ is stronger than $S^{\prime} s$ desire $e_{R}$, it seems plausible to suggest that $S^{\prime} s$ reason to help $T$ in a certain respect is more significant than her reason not to do so. In this case $S$ is rationally justified to perform the former action rather than the latter, although she is not rationally required to do so.

In this section, I have outlined an external feature which provides a possible basis for categorical moral reasons. It is plausible to argue that this suggestion avoids two influential arguments against the existence of categorical reasons. ${ }^{57}$ The first argument is that categorical reasons would be ontologically 'queer' because they would have an 'inbuilt' normative force which cannot plausibly be part of the natural world. However, the external feature under consideration consists in a perfectly mundane natural property (concerning desires agents would have under certain idealized conditions). The second worry is that the notion of categorical reasons entails an implausibly demanding view of rationality. Bernard Williams argued that on this notion the rational considerations involved in a deliberative process mean that an agent who employs them would acquire certain particular desires quite irrespective of what her actual desires consist in. It would be implausible, he objects, that desires could be produced 'ex nihilo' in this way. However, whether $S$ would be able to acquire a desire to $\phi$ (where фing has the mentioned external feature) by employing the rational consideration discussed above depends on her actual desires. Thus, the present suggestion does not entail that employing this consideration would be able to produce desires 'ex nihilo'.

\section{Conclusion}

In this paper, I have outlined an ecumenical view of normative reasons for action which, in my view, has significant advantages compared with competing views. In contrast to internalism, it can account for the existence of categorical moral reasons, since it allows that an agent $\mathrm{S}$ has a

\footnotetext{
${ }^{57}$ For the first objection, see Mackie (1974, 39-40). Cf. Olson (2014, Ch. 6) and Streumer (2017, Ch. 2-3). For the second objection, see Williams (1981, 101-112). Cf. Joyce (2011, Ch. 5).
} 
Dialectica, Vol. 72, 2018, pp. 69-100.

justifying reason to $\phi$ in virtue of $\phi i n g$ having an external feature. In addition, its account of desire-based reasons and rationality is in better accordance with our perceptions of these notions than standard versions of internalism and subjectivism. In contrast to traditional versions of externalism, it provides a straightforward account of the desire-dependency of many everyday reasons, since it entails that $S$ might have a requiring or a justifying reason to $\phi$ in virtue of ding satisfying any of her rational desires. It accounts for the common sense notions that $\mathrm{S}$ might have a moral reason to $\phi$ without being irrational if she lacks a desire to $\phi$, and that we have different rational commitments to ourselves and to others. It entails subjectivism about rationality, which is less philosophically contentious than objectivism. At the same time, it employs overlooked resources in subjectivism so as to vindicate the existence of categorical moral reasons. Lastly, it avoids two standard arguments against the existence of categorical moral reasons. ${ }^{*}$

REFERENCES

ARRUDA, C.T. Forthcoming, "The Varieties of Moral Improvement, or why Metaethical Constructivism must Explain Moral Progress", Ethical Theory and Moral Practice.

BEDKE, M.S. 2010, "Rationalist Restrictions and External Reasons", Philosophical Studies, 151, 1, pp. 39-57.

BuKosKI, M. 2016, “A Critique of Smith's Constitutivism”, Ethics, 127, pp. 116-146.

CHANG, R. 2004, “Can Desires Provide Reasons for Action?”, In R.J. Wallace: Pettit, S. Scheffler, and M. Smith (eds.), Reason and Value, Oxford: Clarendon Press, pp. 56-90.

CHANG, R. 2012, "Are Hard Choices Cases of Incomparability?", Philosophical Issues, 22, 1, pp. 106-126.

CHANG, R. 2013, "Grounding Practical Normativity: Going Hybrid", Philosophical Studies, 164, 1, pp. 163-187.

Copp, D. 1997, "The Ring of Gyges: Overridingness and the Unity of Reason", Social Philosophy and Policy, 14, 1, pp. 86-106.

Copp, D. 2015, "Rationality and Moral Authority", In Shafer-Landau (ed.), Oxford Studies in Metaethics, Vol. 10, Oxford: Oxford University Press, pp. 134-159.

CUlLITY, G. and B. GAUt. 1997, "Introduction”, In G. Cullity and B. Gaut (eds.), Ethics and Practical Reason, Oxford: Clarendon Press.

DANCY, J. 2000, Practical Reality, Oxford: Oxford University Press.

DANCY, J. 2004, "Enticing Reasons", In R.J. Wallace: Pettit, S. Scheffler, and M. Smith (eds.), Reason and Value, Oxford: Clarendon Press, pp. 91-118.

DARWALL, S. (1983), Impartial Reasons, Ithaca: Cornell University Press.

DORSEY, D. 2016, The Limits of Moral Authority, Oxford: Oxford University Press.

ENOCH, D. 2011, Taking Morality Seriously, Oxford: Oxford University Press.

FINLAY, S. 2006, "The Reasons that Matter", Australasian Journal of Philosophy, 84, 1, pp. 1-20.

FINLAY, S. 2008, "The Error in Error Theory", Australasian Journal of Philosophy, 86, 3, pp. 347-369.

FInLAY, S. (2009), "The Obscurity of Internal Reasons", Philosophers' Imprint, 9, pp, 1-22.

FINLAY, S. and Schroeder, M. 2017, "Reasons for Action: Internal vs. External”, Stanford Encyclopedia of Philosophy. FitzPATRICK, W. 2004, "Reasons, Value, and Particular Agents", Mind, 113, 450, pp. 285-318.

Foot, P. 1978, Virtues and Vices, Oxford: Blackwell.

GERT, J. 2002, “Avoiding the Conditional Fallacy", Philosophical Quarterly, 52, 206, pp. 88-95.

GERT, J. 2004, Brute Rationality, Cambridge: Cambridge University Press.

GERT, J. 2007, “Normative Strength and the Balance of Reasons", Philosophical Review, 116, 4, pp. 533-562.

\footnotetext{
* I am very grateful to Joshua Gert, Sarah Stroud, Carla Bagnoli, Caroline Arruda, Louise Clover, Cathrine Felix, and Stefan Schubert for valuable comments on earlier drafts of this paper, and to Philipp Blum and four anonymous reviewers of dialectica for extensive and careful help in improving it. The research presented in the paper was supported by a generous grant from the Swedish Research Council (2012-603).
} 
Dialectica, Vol. 72, 2018, pp. 69-100.

GERT, J. 2009a, "Desires, Reasons, and Rationality”, American Philosophical Quarterly, 46, 4, pp. 319-332.

Gert, J. 2009b, "Response-Dependence and Normative Bedrock", Philosophy and Phenomenological Research, 79, 3, pp. 718-742.

GERT, J. 2012, Brute Rationality, Oxford: Oxford University Press.

Goldman, A. 2009, Reasons from Within, Oxford: Oxford University Press.

HAMPTON, S. (1998), The Authority of Reason, Cambridge: Cambridge University Press.

HARE, R.M. 1981, Moral Thinking, Oxford: Oxford University Press.

Johnson, R. 1999, "Internal Reasons and the Conditional Fallacy", Philosophical Quarterly, 49, 194, pp. 53-71.

JOYCE, R. 2001, The Myth of Morality, Cambridge: Cambridge University Press.

KIESEWETTER, B. 2017, The Normativity of Rationality, Oxford: Oxford University Press.

KorsgaARD, C. 1996, "Skepticism About Practical Reason", In Creating the Kingdom of Ends, Cambridge: Cambridge University Press.

Lillehammer, H. 1999a, "Revisionary Dispositionalism and Practical Reason”, Journal of Ethics, 4, 1, pp. 173-190.

Lillehammer, H. 1999b, "Analytic Dispositionalism and Practical Reason", Ethical Theory and Moral Practice, 2, 2, pp. 117-133.

LILLEHAMMER, H. 2002, “Moral Realism, Normative Reasons, and Rational Intelligibility”, Erkenntnis, 57, 1, pp. 47-62.

LORD, E. 2017, "What You're Rationally Required to Do and What You Ought to Do (Are the Same Thing)", Mind, 126,

504, pp. 1109-1154.

MACKIE, J.L. 1977, Ethics. Inventing Right and Wrong, London: Penguin Books.

Manne, K. (2014), “Internalism about Reasons. Sad but True?”, Philosophical Studies, 167, 1, pp. 89-117.

MARINO, P. 2009, “On Essentially Conflicting Desires", Philosophical Quarterly, 59, 235, pp. 274-291

MARINo, P. 2010, "Moral Rationalism and the Normative Status of Desiderative Coherence", Journal of Moral

Philosophy, 7, 2, pp. 227-252.

Markovits, J. 2014, Moral Reasons, Oxford: Oxford University Press.

NAGEL, T. 1970, The Possibility of Altruism, Princeton: Princeton University Press.

OLson, J. 2014, Moral Error Theory, Oxford: Oxford University Press.

PARFIT, D. 1997, "Reasons and Motivation", Proceedings of the Aristotelian Society, suppl. 71, 1, pp. 99-130.

PARFIT, D. 2011, On What Matters, Vol. I, Oxford: Oxford University Press.

PORTMORE, D.W. 2011, Commonsense Consequentialism, Oxford: Oxford University Press.

PORTMORE, D.W. 2013, “Perform Your Best Option”, Journal of Philosophy, 110, 8, pp. 436-459.

QuinN, W. 1993, "Putting Rationality in its Place", Morality and Action, Cambridge: Cambridge University Press, pp. 228-255.

Rallton, P. 2014, “The Affective Dog and Its Rational Tale", Ethics, 124, 4, pp. 813-859.

RAZ, J. 1999, Engaging Reason, Oxford: Oxford University Press.

RIDGE, M. 2014, Impassioned Belief, Oxford: Oxford University Press.

SAGDAHL, M.S. 2014, "The Argument from Nominal-Notable Comparisons", Journal of Ethics, 18, 4, pp. 405-425.

SCANLON, T.M. 2014, Being Realistic about Reasons, Oxford: Oxford University Press.

Schroeder, M. 2007, Slaves of the Passions, Oxford: Oxford University Press.

SETIYA, K. 2004, “Against Internalism”, Noûs, 38, 2, pp. 266-298.

Shafer-Landau, R. 2003, Moral Realism. A Defence, Oxford: Clarendon.

SHEMmER, Y. 2007, "Desires as Reasons", Philosophy and Phenomenological Research, 75, 2, pp. 326-348.

SIDGWICK, H. 1981, The Methods of Ethics, Indianapolis: Hackett.

SINCLAIR, N. (2017), "Reasons Internalism and the Function of Normative Reasons", dialectica, 71, 2, pp. 209-229.

SMITH, M. 1995, "Internal Reasons", Philosophy and Phenomenological Research, 55, 1, pp. 109-131.

SMIтH, M. 2009, "Desires, Values, Reasons, and the Dualism of Practical Reasons", Ratio, 22, 98, pp. 98-125.

SMITH, M. 2012, "Agents and Patients", Proceedings of the Aristotelian Society, 112, 3, pp. 309-331.

Sobel, D. 2011, "Parfit's Case Against Subjectivism", In Shafer-Landau (ed.), Oxford Studies in Metaethics, Vol. 6,

Oxford: Oxford University Press, pp. 52-78.

SobeL, D. 2016, "Is Subjectivism Incoherent?", Philosophy and Phenomenological Research, 92, 2, pp. 531-538.

StRANDBerg, C. 2017, "A Puzzle about Reasons and Rationality", Journal of Ethics, 21, 1, pp. 63-88.

StREET, S. 2011, "In Defense of Future Tuesday Indifference", Philosophical Issues, 19, pp. 273-298.

StReUmer, B. (2017), Unbelievable Errors, Oxford: Oxford University Press.

SVAVARSDótTIR, S. 2008, "The Virtue of Practical Rationality", Philosophy and Phenomenological Research, 77, 11, pp. $1-33$.

Tiffany, E. 2011, “Deflationary Normative Pluralism”, Canadian Journal of Philosophy, 37, 5, 231-262.

TILLEY, J. 1997, “Motivation and Practical Reasons", Erkenntnis, 47, 1, pp. 105-127. 
Dialectica, Vol. 72, 2018, pp. 69-100.

Velleman, D. 1996, "The Possibility of Practical Reasons", Ethics, 106, 4, pp. 694-726.

Wallace, R.J. (1999), "Three Conceptions of Rational Agency", Ethical Theory and Moral Practice, 2, 3, pp. $217-242$. WEDGWOOD, R. 2017, The Value of Rationality, Oxford: Oxford University Press.

WiLlıAMs, B. 1981, "Internal and External Reasons", Moral Luck, Cambridge: Cambridge University Press, pp. 101113. 